ARTICLE

DOI: $10.1038 / \mathrm{s} 41467-017-00526-3$

\title{
Capture of organic iodides from nuclear waste by metal-organic framework-based molecular traps
}

Baiyan Li (10 1, Xinglong Dong ${ }^{2}$, Hao Wang ${ }^{1}$, Dingxuan Ma ${ }^{3}$, Kui Tan ${ }^{4}$, Stephanie Jensen ${ }^{5}$, Benjamin J. Deibert ${ }^{1}$,

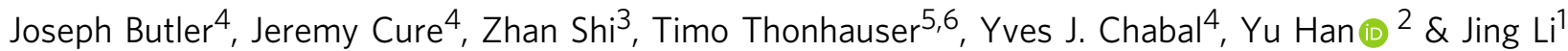

Effective capture of radioactive organic iodides from nuclear waste remains a significant challenge due to the drawbacks of current adsorbents such as low uptake capacity, high cost, and non-recyclability. We report here a general approach to overcome this challenge by creating radioactive organic iodide molecular traps through functionalization of metal-organic framework materials with tertiary amine-binding sites. The molecular trap exhibits a high $\mathrm{CH}_{3}$ l saturation uptake capacity of $71 \mathrm{wt} \%$ at $150^{\circ} \mathrm{C}$, which is more than $340 \%$ higher than the industrial adsorbent $\mathrm{Ag}^{0} @ \mathrm{MOR}$ under identical conditions. These functionalized metal-organic frameworks also serve as good adsorbents at low temperatures. Furthermore, the resulting adsorbent can be recycled multiple times without loss of capacity, making recyclability a reality. In combination with its chemical and thermal stability, high capture efficiency and low cost, the adsorbent demonstrates promise for industrial radioactive organic iodides capture from nuclear waste. The capture mechanism was investigated by experimental and theoretical methods.

\footnotetext{
${ }^{1}$ Department of Chemistry and Chemical Biology, Rutgers University, Piscataway, NJ 08854, USA. ${ }^{2}$ Advanced Membranes and Porous Materials Center, Physical Sciences and Engineering Division, King Abdullah University of Science and Technology, Thuwal 23955-6900, Saudi Arabia. ${ }^{3}$ State Key Laboratory of Inorganic Synthesis and Preparative Chemistry, College of Chemistry, Jilin University, Changchun 130012, People's Republic of China. ${ }^{4}$ Department of Materials Science and Engineering, University of Texas at Dallas, $800 \mathrm{~W}$ Campbell Rd., Richardson, TX 75080, USA. ${ }^{5}$ Department of Physics, Wake Forest University, Winston-Salem, NC 27109, USA. ${ }^{6}$ Department of Chemistry, Massachusetts Institute of Technology, Cambridge, MA 02139, USA.

Correspondence and requests for materials should be addressed to J.L. (email: Jingli@rutgers.edu)
} 
c urrently, nuclear power provides $\sim 11 \%$ of the world's electricity offering a cost-effective option compared to other energy sources ${ }^{1}$. Rapidly increasing global energy needs will likely increase the demand for nuclear energy in the future. Under normal operating conditions, fuel rods used in nuclear power plants need to be reprocessed. This procedure involves the production of complex off-gas mixtures consisting of $\mathrm{HNO}_{3}, \mathrm{NO}_{2}$, and $\mathrm{N}_{2} \mathrm{O}_{5}$ along with radioactive molecular iodine $\left(\mathrm{I}_{2}\right)$ and organic iodides (ROIs, e.g., methyl iodide and ethyl iodide) at elevated temperatures (e.g., $\left.150^{\circ} \mathrm{C}\right)^{2-4}$. Radioactive $\mathrm{I}_{2}$ and ROI species must be selectively captured and sequestered to ensure safe nuclear energy usage. ROI species are known to be particularly difficult to capture, and a recent study has shown that the $\mathrm{CH}_{3} \mathrm{I}$ adsorption rate is only half of that for $\mathrm{I}_{2}$ in the case of $\mathrm{Ag} @ \mathrm{MOR}^{5}$. It thus tends to leak into the environment more easily ${ }^{6}$. Among various current capture technologies, solid sorbent-based fixed-bed methods have proven superior due to their simplicity and relatively low cost ${ }^{7}$. Examples of solid adsorbents for capturing ROIs from off-gas mixtures include triethylenediamine (TED) impregnated activated carbon $(\mathrm{AC})^{8,9}$, and silver impregnated/exchanged solid supports such as silica, alumina, and zeolites ${ }^{10-14}$. Typically the temperature of the offgas is performed at high temperature (such as $\sim 150^{\circ} \mathrm{C}$ ) in order to accelerate the chemical reactions and to remove adsorbed water from the narrow pores of the supports ${ }^{15}$. AC-based adsorbents, however, can only be used under $120^{\circ} \mathrm{C}$ and are limited to specific applications absent of $\mathrm{NO}_{\mathrm{x}}{ }^{16}$ because of low ignition temperatures and the risk of formation of explosive compounds. Silver functionalized porous materials are capable of performing at higher temperatures, but the high costs associated with the noble metal limits their widespread application. Additionally, much to their detriment, chemical adsorption of $\mathrm{CH}_{3} \mathrm{I}-$ necessary for its high uptake at high temperature in such systems-makes the silver-based adsorbents poorly recyclable. Based on these considerations, and the fact that the uptake capacity of all existing adsorbents remains insufficient, new types of adsorbent materials that are noble metal free, highly efficient, cost effective, recyclable, and safe to use, are much needed for ROIs capture.

To tackle the aforementioned challenges, a desired ROI adsorbent must possess the following features: extraordinarily high adsorption capacity at the reprocessing temperature; high tolerance toward nitrogen-based oxides, acidity, and humidity; high thermal stability $\left(\geq 150^{\circ} \mathrm{C}\right)$ that meets the required reprocessing conditions; high efficiency well above reprocessing facility regulatory requirements and low cost and excellent recyclability. To fulfill this goal, we investigate a different type of crystalline porous materials, metal-organic frameworks (MOFs) ${ }^{17-27}$, as tunable and recyclable solid adsorbents for ROIs capture. We reason that such materials can potentially offer the following advantages: large and adjustable surface area and pore size enable accommodation of a large amount of ROI molecules and thus result in high ROI capacity ${ }^{28-38}$; modular nature allows for rational design and tailoring of structural topology and functional sites ${ }^{39-42}$; multivariate syntheses offer possibilities for obtaining topologically identical yet functionally diverse crystalline frameworks ${ }^{43}, 44$; modifiable open metal sites (OMSs) that form reversible coordination bonds with tertiary amines provide an effective means for recyclability ${ }^{45-47}$. While numerous previous investigations have illustrated that MOFs serve as an excellent platform for capture of radioactive molecular iodine $^{32-35,48}$, their use as adsorbent materials to effectively trap ROI species remains unexploited to this date.

Here we demonstrate that highly efficient ROI molecular traps can be obtained via tertiary amine grafting to binding sites within a MOF framework. One such designed molecular trap, MIL-101Cr-TED, exhibits an exceptionally high uptake capacity of $71 \mathrm{wt} \%$ for methyl iodide at $150^{\circ} \mathrm{C}$. Under identical capture conditions, this performance is more than $340 \%$ higher than that of the industrial adsorbent $\mathrm{Ag}^{0} @ \mathrm{MOR}$, a leading material in the United

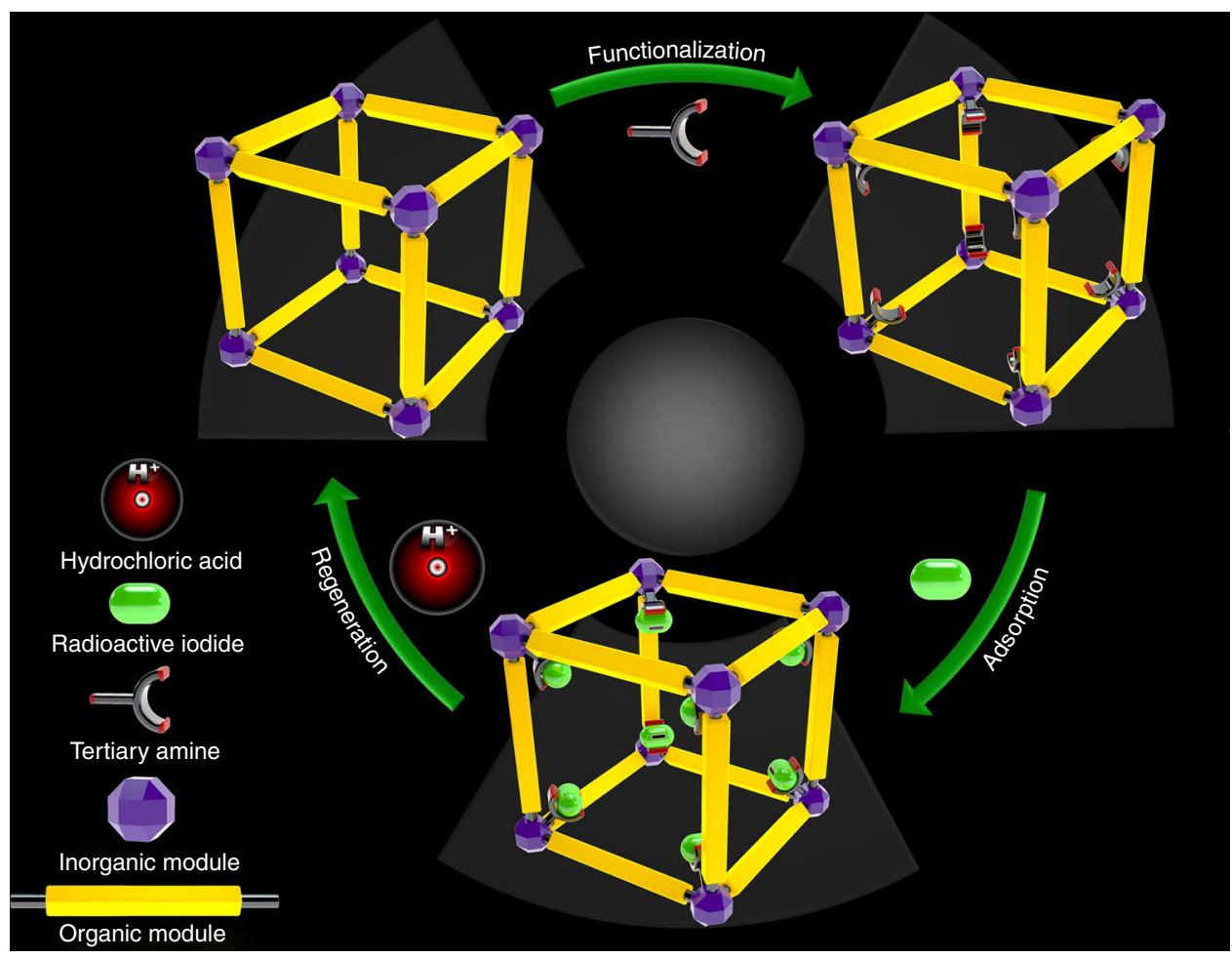

Fig. 1 The design strategy. A schematic illustrating the design of a recyclable MOF molecular trap for effective capture of radioactive organic iodides from nuclear waste 
a

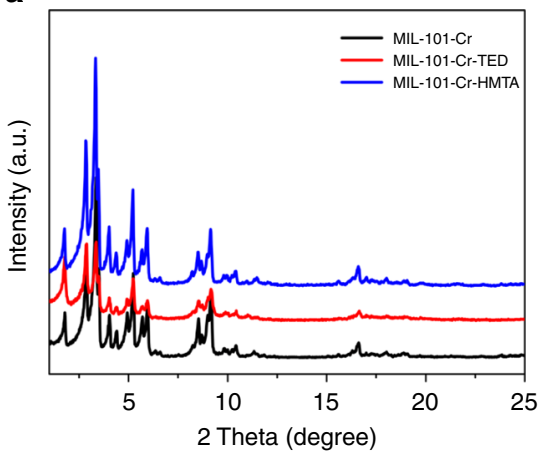

C

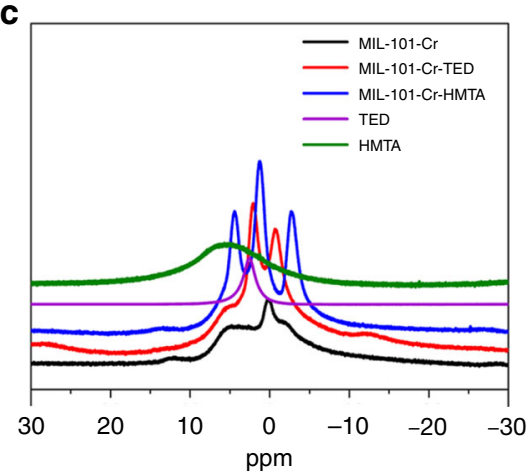

b

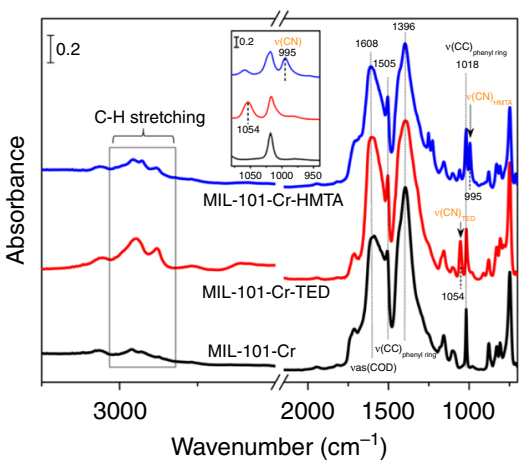

d

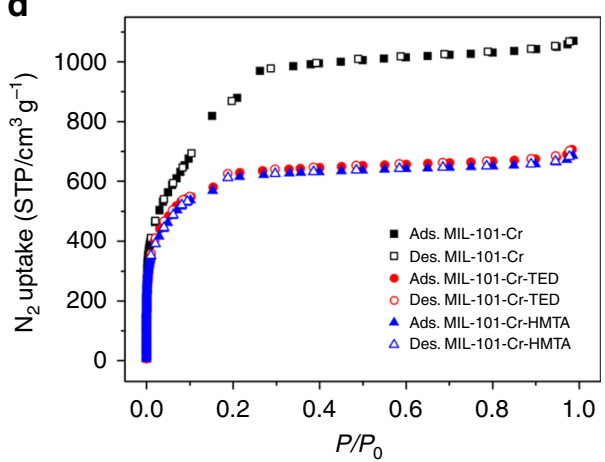

Fig. 2 Characterization of MIL-101-Cr and tertiary amine functionalized MIL-101-Cr. a PXRD patterns of MIL-101-Cr, MIL-101-Cr-TED, and MIL-101-CrHMTA. b FT-IR spectra of MIL-101-Cr, MIL-101-Cr-TED, and MIL-101-Cr-HMTA collected on samples after dehydration at $150^{\circ} \mathrm{C}$, the inset shows the mode associated with the C-N stretching vibration, at $1054 \mathrm{~cm}^{-1}$ in MIL-101-Cr-TED and $995 \mathrm{~cm}^{-1}$ in MIL-101-Cr-HMTA, based on refs 51,52 . Note that the weak band at $1059 \mathrm{~cm}^{-1}$ in MIL-101-Cr-HMTA spectrum is due to the CNC deformation vibration. The assignment of MOF phonon modes are based on ref. 53 . c Solid ${ }^{1} \mathrm{H}$ NMR spectra of MIL-101-Cr, TED, HMTA, MIL-101-Cr-TED, and MIL-101-Cr-HMTA. d N ${ }_{2}$ sorption isotherms of MIL-101-Cr, MIL-101-Cr-TED, and MIL-101-Cr-HMTA collected at $77 \mathrm{~K}$

States for ROIs capture ${ }^{10,49}$. Furthermore, the pristine MOF sample can be regenerated and reused multiple times without decrease in uptake capacity. This is a notable advancement as high-temperature recyclable adsorbent materials have been pursued since the 1980s but with very little success to this date. Coupled with its high chemical and thermal stability, relatively low cost, and high capture efficiency at both room and high temperatures, amine functionalized MIL-101-Cr-TED demonstrates a considerable potential for use as MOF-based adsorbent for the ROIs capture technology. Employing both experimental and theoretical methods, we further carried out an in-depth study to investigate and understand the mechanism of $\mathrm{CH}_{3}$ I capture in the MIL-101-Cr-TED system. Our findings show that the construction and optimization of such molecular traps can be expanded to other MOFs by a suitable combination of robust frameworks with strong binding sites and tertiary amine molecules, which may lead to a large number of ROI capture materials. This strategy thus paves the way for further research and advancement on MOF-based molecular traps for their ultimate utility in ROIs capture from nuclear waste.

\section{Results}

Synthesis and characterization. To construct high performance molecular traps (Fig. 1) that are highly stable, efficient, and recyclable for capturing organic iodides, we chose MIL-101-Cr as a model support material because of its large surface area $\left(>3300 \mathrm{~m}^{2} \mathrm{~g}^{-1}\right)$, high acid and moisture stability, thermal stability $\left(\sim 300^{\circ} \mathrm{C}\right)$, and relatively low cost ${ }^{44}$. Two tertiary amines, triethylenediamine (TED) and hexamethylenetetramine
(HMTA), were selected as functional molecules for post-synthetic modification of the MOF framework. Both species can use a single nitrogen to bind to the OMSs on the $\mathrm{Cr}$ trinuclear secondary building unit of MIL-101-Cr $\mathrm{C}^{45}, 47,50,51$, with the remaining nitrogen atoms available as binding sites for organic iodides (Supplementary Fig. 1). MIL-101-Cr-TED and MIL-101Cr-HMTA were obtained by stirring MIL-101-Cr with TED or HMTA in benzene or chloroform at $110^{\circ} \mathrm{C}$ for $24 \mathrm{~h}$ in a resealed flask under nitrogen atmosphere. Transmission electron microscopy (TEM) images (Supplementary Fig. 2) of both functionalized MOFs show similar crystal morphology when compared to as-made MIL-101-Cr, suggesting retention of crystallinity and morphology after amine functionalization.

The successful grafting of tertiary amine groups onto MIL-101Cr was confirmed by powder X-ray diffraction (PXRD), Fourier transform infrared (FT-IR) spectroscopy, X-ray photoelectron spectroscopy (XPS), solid-state ${ }^{1} \mathrm{H}$ NMR, and elemental analysis. PXRD analysis shows that the diffraction profiles are unchanged after amine functionalization (Fig. 2a), indicating that the crystal structure of the functionalized material remains intact. The IR absorption spectra in Fig. 2b shows two additional peaks (at 1054 and $995 \mathrm{~cm}^{-1}$ ) associated with TED and HMTA that are not present in pristine MIL-101-Cr. This amine-associated mode (see inset of Fig. 2b) is attributed to the skeletal C-N stretching mode ${ }^{52}, 53$, confirming successful grafting. In addition, new features between 3000 and $2800 \mathrm{~cm}^{-1}$ are assigned to the aliphatic C-H stretching modes of TED and HMTA molecules (Fig. 2b) ${ }^{52,53}$. XPS spectra (Supplementary Fig. 3) confirm that the $\mathrm{N}(1 \mathrm{~s})$ core level in MIL-101-Cr-TED and MIL-101-CrHMTA is at a binding energy $(\sim 400.0 \mathrm{eV})$ consistent with the 
a

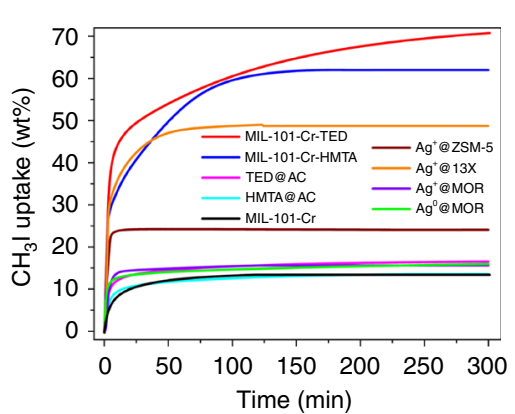

d

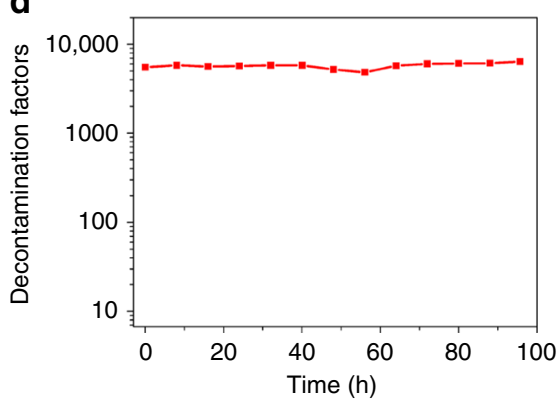

b

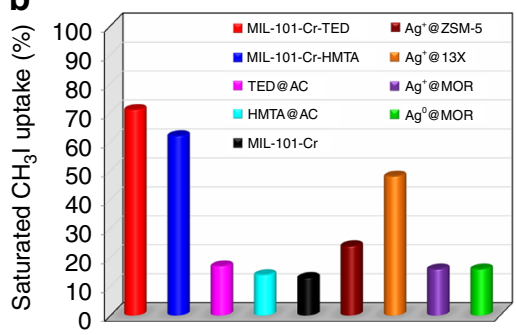

e

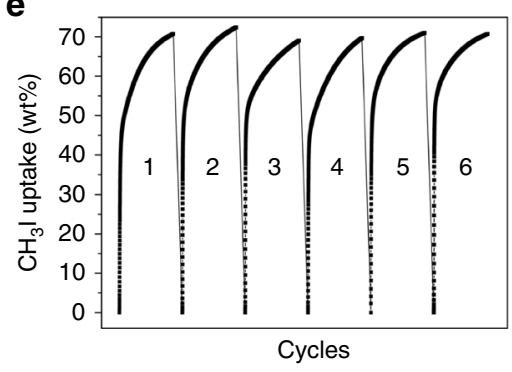

C
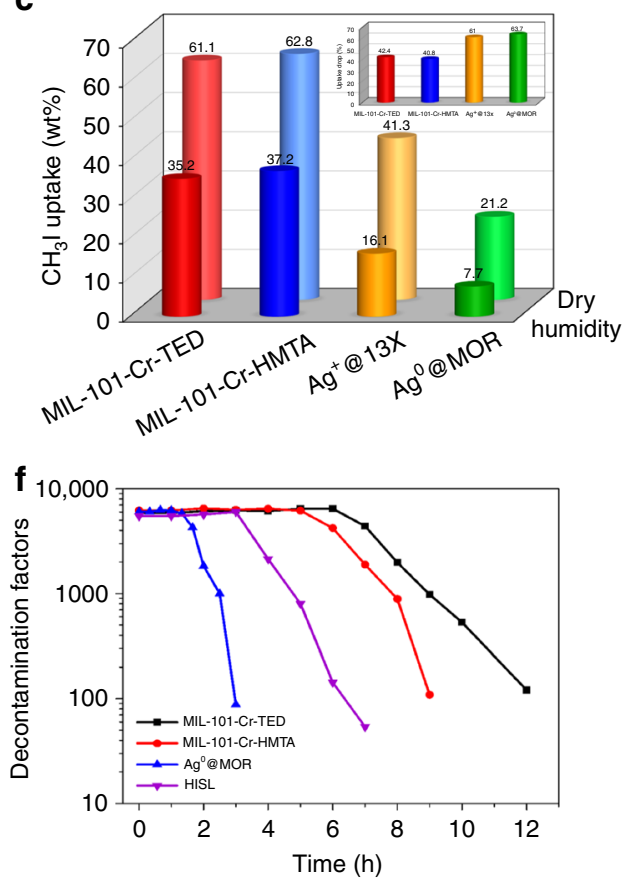

Fig. 3 The $\mathrm{CH}_{3} \mathrm{I}$ capture performance. a Sorption isotherms of $\mathrm{CH}_{3} \mathrm{I}$ in MIL-101-Cr-TED, MIL-101-Cr-HMTA, and selected benchmark sorbent materials at $150^{\circ} \mathrm{C}$ with partial pressure of $0.2 \mathrm{~atm}$ for $\mathrm{CH}_{3}$ l. b Comparing the saturated $\mathrm{CH}_{3}$ l uptake in MIL-101-Cr-TED, MIL-101-Cr-HMTA, and selected benchmark sorbent materials at $150^{\circ} \mathrm{C}$ with partial pressure of $0.2 \mathrm{~atm}$ for $\mathrm{CH}_{3} \mathrm{l}$. c The $\mathrm{CH}_{3}$ l uptake at $150{ }^{\circ} \mathrm{C}$ under dry and humidity $(\mathrm{RH}=81 \%)$ conditions by breakthrough experiment (back row: dry conditions; front row: humid conditions), (insert) the uptake drop ratio by comparing the $\mathrm{CH}_{3} \mathrm{l}$ uptake of dry and humid conditions. $\mathbf{d}$ Decontamination factors of $\mathrm{CH}_{3}$ l by MIL-101-Cr-TED under simulated conditions representing gas mixtures produced during $\mathrm{CH}_{3} \mathrm{l}$ reprocessing, which include $\mathrm{CH}_{3} \mathrm{I}(50 \mathrm{ppm}), \mathrm{H}_{2} \mathrm{O}, \mathrm{HNO}_{3}, \mathrm{NO}_{2}$, and $\mathrm{NO}$ at $150{ }^{\circ} \mathrm{C}$. e The recyclability of MIL-101-Cr-TED for $\mathrm{CH} / \mathrm{l}$ capture. f Decontamination factors of total iodine $\left(\mathrm{CH}_{3} \mathrm{I}\right.$ and $\left.\mathrm{I}_{2}\right)$ by MIL-101-Cr-TED, MIL-101-Cr-HTMA, and comparable samples Ag @MOR and HISL under the simulated conditions of an off-gas mixture: $\mathrm{I}_{2}(150 \mathrm{ppm}), \mathrm{CH}_{3} \mathrm{I}(50 \mathrm{ppm}), \mathrm{H}_{2} \mathrm{O}, \mathrm{HNO}_{3}$ and $\mathrm{NO}_{x}$ at $150{ }^{\circ} \mathrm{C}$

nitrogen within tertiary amine groups ${ }^{54}$. Solid-state ${ }^{1} \mathrm{H}$ NMR studies identify chemical shifts at 2.1 and $1.3 \mathrm{ppm}$ for the hydrogen of $-\mathrm{CH}_{2}-$ groups in TED and HMTA (Fig. 2c) ${ }^{55}$. These observations establish that TED and HMTA are chemically incorporated onto the OMSs. Elemental analysis reveals a nitrogen content of 6.38 and $12.15 \mathrm{wt} \%$ for MIL-101-Cr-TED and MIL-101-Cr-HMTA, respectively. This is equivalent to $\sim 2 / 3$ TED or HMTA molecules grafted to each $\mathrm{Cr}$, which is consistent with the previous report of two available open metal sites on each $\mathrm{Cr}_{3} \mathrm{O}$ cluster $(2: 3)^{45}$.

Nitrogen gas adsorption-desorption isotherms collected at $77 \mathrm{~K}$ indicate that the modification of TED and HMTA molecules onto MIL-101-Cr leads to a decrease in the Brunauer-Emmett-Teller surface area from 3342 to $2282 \mathrm{~m}^{2} \mathrm{~g}^{-1}$ and $2272 \mathrm{~m}^{2} \mathrm{~g}^{-1}$ for MIL-101-Cr-TED and MIL-101-Cr-HMTA, respectively (Fig. 2d). Despite such decreases, the surface areas of the two aminefunctionalized samples are significantly higher than any other benchmark porous materials, which usually exhibit moderate surface areas of $\sim 300-1000 \mathrm{~m}^{2} \mathrm{~g}^{-110-14}$. Based on the pore size distribution (Supplementary Fig. 4), both MIL-101-Cr-TED and MIL-101-Cr-HMTA have pore diameters of about 16 and $21 \AA$, which are large enough for effective mass transfer during nuclear waste reprocessing. Thermogravimetric analysis (TGA) shows that MIL-101-Cr-TED and MIL-101-Cr-HMTA are stable up to 260 and $220^{\circ} \mathrm{C}$, respectively (Supplementary Note 1 and Supplementary Fig. 5). Isothermal TG analysis of amine grafted MIL-101-Cr samples clearly show that both TED and HMTA remain attached to the framework without losing mass upon prolonged heating at $150{ }^{\circ} \mathrm{C}$ for $12 \mathrm{~h}$ (Supplementary Fig. 6). The high thermal stability of the two compounds enables their use at the elevated working temperature (such as $150^{\circ} \mathrm{C}$ ) required for nuclear waste treatment. This result is consistent with the high binding energies of TED and HMTA to the OMSs (Supplementary Note 2, Supplementary Fig. 7, and Supplementary Table 1) obtained from ab initio theoretical calculations. The calculations also show that the TED and HMTA bind significantly more strongly to the OMSs compared to $\mathrm{H}_{2} \mathrm{O}$ molecules, further suggesting the feasibility of their application under humid conditions. In addition, two materials also show excellent stability in both $\mathrm{CH}_{3} \mathrm{I}$ gas stream and simulated off-gas mixture, as evident from the PXRD patterns collected after the experiments (Supplementary Fig. 8). The large surface area coupled with the high thermal and chemical stability of both MIL-101-Cr-TED and MIL-101-Cr-HMTA prompted us to evaluate their performance as molecular traps for the removal of ROIs from off-gas mixtures.

Radioactive organic iodides sorption studies. To evaluate the performance of MIL-101-Cr-TED and MIL-101-Cr-HMTA for ROIs capture, as-made samples ( $20 \mathrm{mg}$ of each) were placed in a thermogravimetric analyzer and a $\mathrm{CH}_{3} \mathrm{I}$ steam with partial pressure of 0.2 atm was passed through the sample cell using $\mathrm{N}_{2}$ as a carrier gas. The adsorption amount was monitored by recording sample mass as a function of time. As shown in Supplementary Fig. 9, MIL-101-Cr-TED and MIL-101-CrHMTA rapidly absorb 120 and $136 \mathrm{wt} \% \mathrm{CH}_{3} \mathrm{I}$ within $10 \mathrm{~min}$ at $30{ }^{\circ} \mathrm{C}$ and reach their maximum uptake amount of 160 and $174 \mathrm{wt} \%$ by $120 \mathrm{~min}$, respectively. The absorption amounts are significantly higher than all benchmark materials used for $\mathrm{CH}_{3} \mathrm{I}$ adsorption under the same conditions, such as TED- and HMTAimpregnated activated carbon (TED@AC and HMTA@AC) 
and silver functionalized zeolites (including ZSM-5, 13X, and mordenite $\quad\left(\mathrm{Ag}^{+} @ \mathrm{ZSM}-5, \quad \mathrm{Ag}^{+} @ 13 \mathrm{X}, \quad \mathrm{Ag}^{+} @ \mathrm{MOR}, \quad\right.$ and $\mathrm{Ag}^{0} @ \mathrm{MOR}$ ) with $\mathrm{CH}_{3} \mathrm{I}$ uptake amounts of $52,54,28,45,29$, and $25 \mathrm{wt} \%$, respectively (Supplementary Fig. 10)).

Since the capture of organic iodides from off-gas mixtures is usually performed at elevated temperatures (e.g., $\left.\sim 150^{\circ} \mathrm{C}\right)^{15}$, we tested the $\mathrm{CH}_{3} \mathrm{I}$ uptake capacity at $150^{\circ} \mathrm{C}$ for both samples and several benchmark materials. MIL-101-Cr-TED and MIL-101-CrHMTA can fast adsorb 48 and $39 \mathrm{wt} \% \mathrm{CH}_{3} \mathrm{I}$ within $20 \mathrm{~min}$ (Fig. 3a). For the same time period, $\mathrm{Ag}^{0} @ \mathrm{MOR}$ (the industrial zeolite material) only shows a $\mathrm{CH}_{3} \mathrm{I}$ uptake of $13 \mathrm{wt} \%$ under the same conditions. The fast adsorption rate of MIL-101-Cr-TED and MIL-101-Cr-HMTA is an important feature for practical applications of radioactive $\mathrm{CH}_{3} \mathrm{I}$ capture. The kinetic constants of MIL-101-Cr-TED and MIL-101-Cr-HMTA were calculated to be 0.30 and 0.36 , respectively (Supplementary Note 3 and Supplementary Table 2), based on Lagergren's pseudo first-order kinetic model. These values are similar as of other comparable materials, which have kinetic constant values between 0.19 and 0.62 (Supplementary Table 2 and Supplementary Fig. 11). At this temperature, the maximum uptake amounts at $0.2 \mathrm{~atm}$ are 71 and $62 \mathrm{wt} \%$ for MIL-101-Cr-TED and MIL-101-Cr-HMTA, respectively (Fig. 3a). These values are 4.4 and 3.9 times that of $\mathrm{Ag}^{0} @ \mathrm{MOR}$ (16 wt\%), a leading adsorbent material for capturing ROIs in the US nuclear fuel reprocessing industry ${ }^{48}$. We also compared the performance of MIL-101-Cr-TED with $\mathrm{Ag}^{+} @ 13 \mathrm{X}$, a zeolite with the highest silver content. $\mathrm{Ag}^{+} @ 13 \mathrm{X}$ has a higher $\mathrm{CH}_{3} \mathrm{I}$ uptake amount (max. 48 wt $\%$ ) compared to $\mathrm{Ag}^{0} @ \mathrm{MOR}$, but its low-acid resistance presents a serious drawback. MIL-101-CrTED adsorbs 1.5 times more $\mathrm{CH}_{3} \mathrm{I}$ than $\mathrm{Ag}^{+} @ 13 \mathrm{X}$ under identical conditions. The capture capacity of MIL-101-Cr-TED is also much higher than the other benchmark materials, such as TED@AC, HMTA@AC, Ag $@ Z S M-5$, and $\mathrm{Ag}^{+} @ M O R$, with uptake amounts of 17, 14, 24, and $16 \mathrm{wt} \%$, respectively (Fig. 3b). Compared to the performance of pristine MIL-101-Cr $\left(\mathrm{CH}_{3} \mathrm{I}\right.$ uptake: $\left.13 \mathrm{wt} \%\right)$, TED functionalization leads to a remarkable increase of $\sim 5.5$ times. Based on these comparisons, MIL-101-Cr-TED clearly ranks as the top candidate for adsorbent-based capture and removal of ROIs during nuclear fuel reprocessing. The exceptionally high uptake capacity of tertiary amine functionalized MIL-101-Cr can be attributed to two main factors: (a) relatively high surface area of the adsorbent after functionalization, and more importantly, (b) effective grafting of TED and HMTA onto the MOF pore surface (via OMSs) creating molecular traps that offer greatly enhanced bonding interactions toward organic iodides. In addition, we performed adsorption experiments on two other organic iodides, $\mathrm{CH}_{3} \mathrm{CH}_{3} \mathrm{I}$ and $\mathrm{CH}_{3} \mathrm{CH}_{2} \mathrm{CH}_{2} \mathrm{I}$. High uptake amounts were achieved for both species: 75 and $51 \mathrm{wt} \%$ of $\mathrm{CH}_{3} \mathrm{CH}_{3} \mathrm{I}$ and 74 and $54 \mathrm{wt} \%$ of $\mathrm{CH}_{3} \mathrm{CH}_{2} \mathrm{CH}_{3} \mathrm{I}$ in MIL-101-Cr-TED and MIL-101Cr-HMTA, respectively (Supplementary Fig. 12).

To assess the influence of humidity on the organic iodide uptake capacity, a crucial aspect for a sorbent's performance metrics in real-world applications, we performed column breakthrough tests at $150^{\circ} \mathrm{C}$ under both dry and humid conditions $\left(\mathrm{RH}=81 \%\right.$ at $23^{\circ} \mathrm{C}$ ) (Supplementary Figs. 13-16 and Supplementary Table 3). For $\mathrm{Ag}^{+} @ 13 \mathrm{X}$, the zeolite with the best performance based on our parallel experimental results, the uptake drops from 41.3 to $16.1 \mathrm{wt} \%$, a significant decrease of $61 \%$ (Fig. 3c, insert). We also observed a dramatic decrease of $63.7 \%$ for $\mathrm{Ag}^{0} @ \mathrm{MOR}$, with an uptake of $21.2 \mathrm{wt} \%$ under dry conditions and $7.7 \mathrm{wt} \%$ under humid conditions. For MIL-101-Cr-TED and MIL-101-Cr-HMTA, however, the extent of decrease is much smaller ( 42.4 and $40.8 \%$, respectively). Based on the breakthrough data, the uptake capacities of MIL-101-Cr-TED and MIL-101-CrHMTA are 2.2 and 2.3 times higher than that of $\mathrm{Ag}^{+} @ 13 \mathrm{X}$, and
4.6 and 4.8 times greater than $\mathrm{Ag}^{0} @ \mathrm{MOR}$ at $150^{\circ} \mathrm{C}$ under humid conditions, underscoring the robustness of MIL-101-Cr-TED and MIL-101-Cr-HMTA adsorbents in humid environments. The higher hydrophilicity of zeolites compared to MOF materials may account for this difference, which makes MOFs are an advantageous platform for $\mathrm{CH}_{3} \mathrm{I}$ capture over conventional silver functionalized zeolites. As in the cases of previous studies ${ }^{8}$, moisture will affect the performance of capture materials. The decrease in the $\mathrm{CH}_{3} \mathrm{I}$ uptake capacity under humidity is likely due to the fact that a large amount of water molecules will take up the chemisorption sites and porous space, thereby reducing the overall loading amount.

Nuclear processing facilities' regulatory standards require a "decontamination factor" (DF) of 3000 (99.967\% of active species removed) for $\mathrm{CH}_{3} \mathrm{I}$ reprocessing, which is defined as the ratio of radioactivity before and after decontamination procedures ${ }^{56}$. To evaluate the efficiency of MIL-101-Cr-TED as a molecular trap for capturing $\mathrm{CH}_{3} \mathrm{I}$ from nuclear waste, we performed breakthrough experiments under conditions simulating the gas mixtures produced during $\mathrm{CH}_{3} \mathrm{I}$ reprocessing, which include $\mathrm{H}_{2} \mathrm{O}, \mathrm{HNO}_{3}, \mathrm{NO}_{2}$, and $\mathrm{NO}$ at $150^{\circ} \mathrm{C}^{56}$. As shown in Fig. $3 \mathrm{~d}$, for a very low $\mathrm{CH}_{3} \mathrm{I}$ concentration of $50 \mathrm{ppm}$ that mimics real-world off-gas reprocessing conditions, very high DFs for MIL-101-CrTED are achieved, with the values range between 4800 and 6300 , which are substantially higher than the reprocessing facility regulatory requirements ${ }^{57}$. This means that about $99.979-$ 99.984\% $\mathrm{CH}_{3} \mathrm{I}$ can be removed by MIL-101-Cr-TED under such conditions. The result further illustrates that the MOF-based molecular traps are highly suitable for ROIs capture from nuclear waste off-gas mixtures.

After $\mathrm{CH}_{3} \mathrm{I}$ adsorption, pristine MIL-101-Cr can be regenerated by washing with $3 \mathrm{M} \mathrm{HCl}$ followed by ethanol solution, resulting in complete recovery of the pristine MOF sample (Supplementary Figs. 17 and 18). The framework can then be refunctionalized to MIL-101-Cr-TED or MIL-101-Cr-HMTA following the initial procedure. The regenerated MIL-101-CrTED retains $\sim 97-100 \%$ of the original loading capacity during the five full cycles (Fig. 3e). As silver-based adsorbents often suffer from a dramatic loss of adsorption capacity after only a few cycles (e.g., 50\% loss for $\mathrm{Ag}^{+} @ 13 \mathrm{X}$ after five cycles), our investigation thus established a recyclable system for ROIs capture from nuclear waste that is unattainable by any other known high-temperature adsorbents. We also estimated the $\mathrm{CH}_{3} \mathrm{I}$ capture cost for MIL-101-Cr-TED and $\mathrm{Ag}^{0} @ \mathrm{MOR}$. As shown in Supplementary Table 4, for each cycle the cost for the latter is 35 times of the former, a significant saving for MIL-101-Cr-TED.

To evaluate the material capability of capturing ROIs under the real-world conditions, we also conducted breakthrough experiments (Fig. 3f and Supplementary Fig. 19) at the conditions that mimic an off-gas mixture with high humidity $(\mathrm{RH}=95 \%)$ and in the presence of $\mathrm{HNO}_{3}$ and $\mathrm{NO}_{\mathrm{x}}$. The mixture also contains both radioactive species $\mathrm{I}_{2}(150 \mathrm{ppm})$ and $\mathrm{CH}_{3} \mathrm{I}(50 \mathrm{ppm})$. At $150^{\circ} \mathrm{C}$, the total iodine uptake amounts calculated based on unit weight and unit volume, as well as packing density of the sorbents (Supplementary Fig. 20) are summarized in Supplementary Table 5. The uptake are 38 and $33 \mathrm{wt} \%$ for MIL-101-Cr-TED and MIL-101-Cr-HMTA, respectively, and high DF values $(>5000)$ are obtained (Fig. $3 \mathrm{f}$ and Supplementary Table 5). These values are significant higher than those of $\mathrm{Ag}^{0} @ \mathrm{MOR}(5 \mathrm{wt} \%)^{12}$ and pure silica zeolite HISL $(16 \mathrm{wt} \%)^{15}$ under the same conditions (Fig. 3f and Supplementary Table 5). The results suggest that amine grafted MIL-101-Cr materials are capable of effectively capturing $\mathrm{CH}_{3} \mathrm{I}$ in off-gas mixtures containing $\mathrm{I}_{2}$. In addition, $\mathrm{I}_{2}$ adsorption isotherms were collected under similar experimental conditions $\left(150^{\circ} \mathrm{C}\right.$ and $\left.150 \mathrm{ppm}\right)$ and its interaction with amine functionalized MIL-101-Cr were evaluated 
a

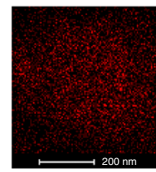

$\mathrm{C}$

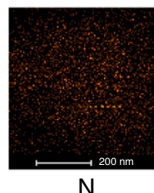

$\mathrm{N}^{20}$

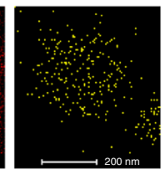

I-K

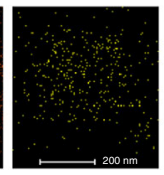

O

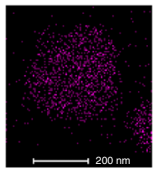

$\mathrm{I}-\mathrm{L}$

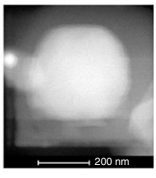

d
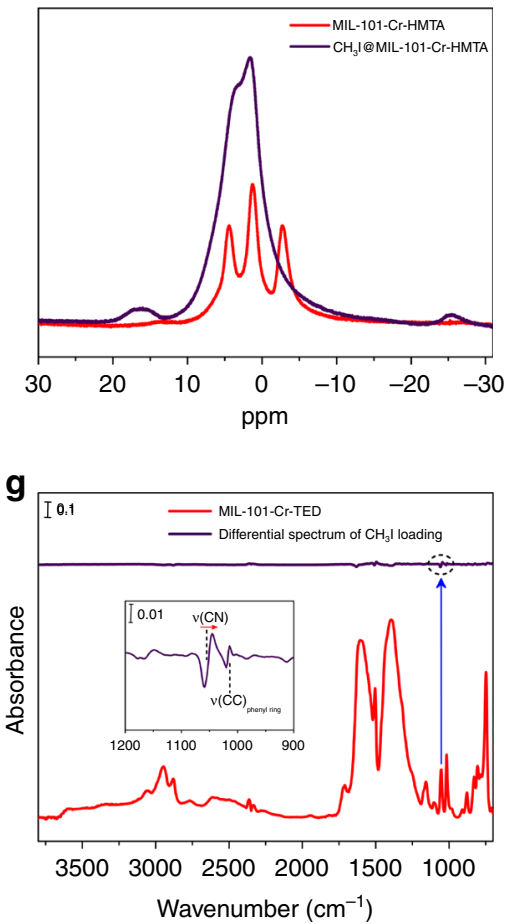

b

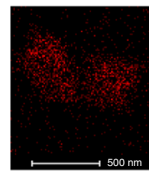

${ }^{\mathrm{C}}$
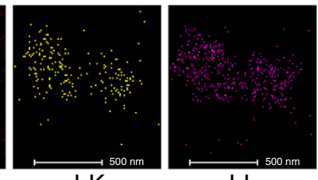

I-K
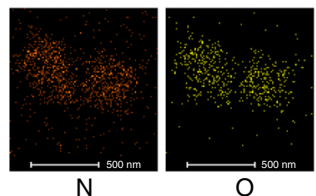

$\mathrm{O}$

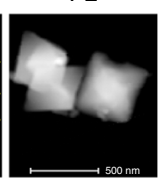

e

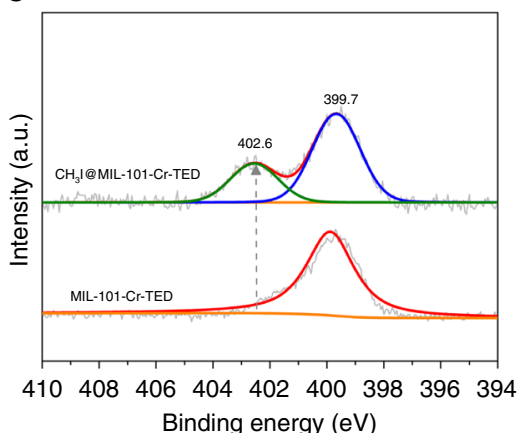

h

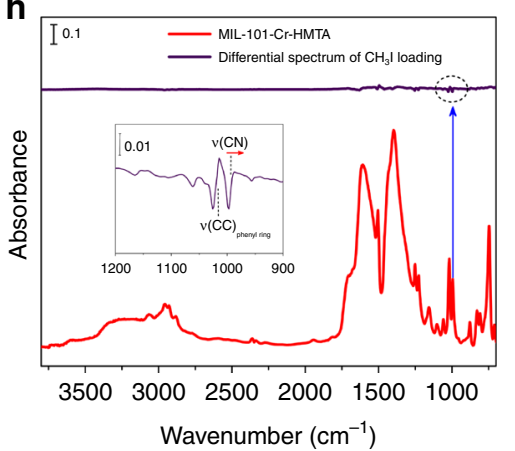

C

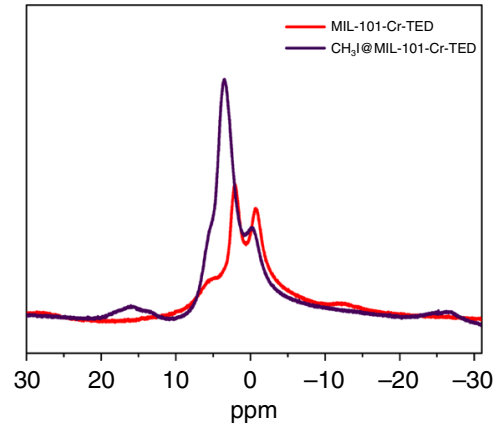

f

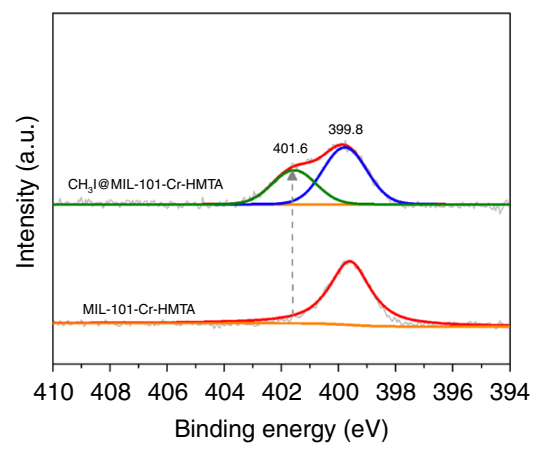

i

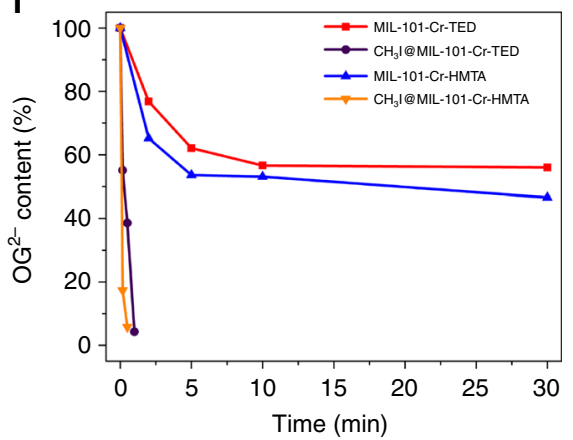

Fig. 4 The mechanism of $\mathrm{CH}_{3}$ l capture by MIL-101-Cr-TED and MIL-101-Cr-HMTA. a The elemental mapping of CH $\mathrm{H}_{3}$ loaded MIL-101-Cr-TED. b The elemental mapping of $\mathrm{CH}_{3}$ l loaded MIL-101-Cr-HMTA. c Solid ${ }^{1} \mathrm{H}$ NMR spectra of MIL-101-Cr-TED and $\mathrm{CH}_{3} \mathrm{l} @$ MIL-101-Cr-TED. d Solid ${ }^{1} \mathrm{H}$ NMR spectra of MIL-101-Cr-HMTA and CH 1 @MIL-101-Cr-HMTA. e XPS spectra of N(1s) for MIL-101-Cr-TED and CH $1 @$ @IL-101-Cr-TED (gray, experiment curves; red, blue, and green: fitted curves; orange: baselines). f XPS spectra of N(1s) for MIL-101-Cr-HMTA and CH $3 @ @ M I L-101-C r-H M T A$ (gray, experiment curves; red, blue, and green: fitted curves; orange: baselines). $\mathbf{g}$ In situ IR spectra (green) of $\sim 150$ Torr $\mathrm{CH}_{3}$ l exposed MIL-101-Cr-TED referenced to the activated MIL-101-Cr-TED; and IR absorption spectra (red) of activated MIL-101-Cr-TED referenced to $\mathrm{KBr}$ pellet in vacuum ( $<20 \mathrm{mtorr}$ ). $\mathbf{h}$ In situ IR spectra (green) of 150 Torr $\mathrm{CH}_{3}$ lexposed MIL-101-Cr-HMTA referenced to the activated MIL-101-Cr-HMTA; and IR absorption spectra (red) of activated MIL-101-Cr-HMTA referenced to $\mathrm{KBr}$ pellet ( $<20$ mtorr). i lon exchange efficiencies of an anionic dye (Orange G or OG) by pristine MIL-101-Cr-TED and MIL-101-Cr-HMTA and functionalized $\mathrm{CH}_{3} \mathrm{l} @$ MIL-101-Cr-TED and $\mathrm{CH}_{3}$ @MIL-101-Cr-HMTA as a function of time

(Supplementary Note 4 and Supplementary Figs. 21-23). The possible adsorption mechanisms in simulated gas mixture were also investigated and binding energies were estimated by DFT calculations (Supplementary Note 2, Supplementary Fig. 24, and Supplementary Table 6). Similar experiments were also performed at room temperature, which gives the same trend (Supplementary Table 5). Furthermore, recyclability tests of MIL101-Cr-TED under simulated off-gas conditions verified that the total iodine uptake remains the same after three cycles (Supplementary Fig. 25).

Investigation of $\mathrm{CH}_{3} \mathrm{I}$-binding interactions mechanisms. The outstanding performance of MIL-101-Cr-TED and MIL-101Cr-HMTA encouraged us to investigate the possible interaction mechanisms between $\mathrm{CH}_{3} \mathrm{I}$ molecules and the MOF host. Gas adsorption experiments carried out at $150{ }^{\circ} \mathrm{C}$ show evidence of both physisorption and chemisorption for $\mathrm{CH}_{3} \mathrm{I}$ (Supplementary Fig. 26), but chemisorption is the dominant mode of interaction (76 and 68\% for MIL-101-Cr-TED and MIL-101-Cr-HMTA, respectively) at that temperature, with most $\mathrm{CH}_{3} \mathrm{I}$ molecules being chemically trapped within the framework. The chemisorbed amounts are 54 and $43 \mathrm{wt} \%$, respectively, for MIL-101-Cr-TED and MIL-101-Cr-HMTA, and physisorbed amounts, 17 and $19 \mathrm{wt} \%$, respectively. The partial pressure of $\mathrm{CH}_{3} \mathrm{I}$ shows very little influence on the chemisorption capacity of the sorbents (Supplementary Fig. 27).

The strong interaction between $\mathrm{CH}_{3} \mathrm{I}$ molecules and MIL-101Cr-TED and MIL-101-Cr-HMTA was verified by HRTEM-EDS, solid-state ${ }^{1} \mathrm{H}$ NMR, XPS, and in situ FT-IR studies. Elemental 
mapping using HRTEM-EDS confirms uniformly dispersed iodine $\left(\mathrm{CH}_{3} \mathrm{I}\right)$ within the crystal samples of $\mathrm{CH}_{3} \mathrm{I}$-loaded MIL-101-Cr-TED and MIL-101-Cr-HMTA (Fig. 4a, b). Solidstate ${ }^{1} \mathrm{H}$ NMR spectra of $\mathrm{CH}_{3} \mathrm{I}$-loaded MIL-101-Cr-TED and MIL-101-Cr-HMTA show a new peak at $\sim 16$ ppm (Fig. $4 c, d$ ), which can be assigned to the $\mathrm{H}$ atoms of $\mathrm{CH}_{3} \mathrm{I}^{58}$. The XPS data are consistent with this interpretation, as a good fraction of the $\mathrm{N}(1 \mathrm{~s})$ core level is shifted to higher binding energies upon $\mathrm{CH}_{3} \mathrm{I}$ loading (402.6 and $401.6 \mathrm{eV}$ for MIL-101-Cr-TED and MIL-101-Cr-HMTA, respectively) as compared with the as-synthesized analogs. This shift indicates that the valence of $\mathrm{N}$ is increased by interacting with guest $\mathrm{CH}_{3} \mathrm{I}$ molecules (Fig. 4e, f). The $\mathrm{N}(1 \mathrm{~s})$ core level shifts more in $\mathrm{CH}_{3} \mathrm{I} @ \mathrm{MIL}-101$ Cr-TED, $2.9 \mathrm{eV}$, compared to $1.8 \mathrm{eV}$ in $\mathrm{CH}_{3} \mathrm{I} @ \mathrm{MIL}-101-\mathrm{Cr}-$ HMTA, indicating less charge transfer in $\mathrm{CH}_{3} \mathrm{I} @ \mathrm{MIL}-101-\mathrm{Cr}-$ HMTA. Consistent with this interaction, the I $3 \mathrm{~d}_{5 / 2}$ peak of $\mathrm{CH}_{3} \mathrm{I}$, positioned at $620.2 \mathrm{eV}$ for the molecular adsorbed state, was red shifted to $618.7 \pm 0.1 \mathrm{eV}$ in MIL-101-Cr-TED and to $618.6 \pm 0.1 \mathrm{eV}$ in MIL-101-Cr-HMTA (Supplementary Fig. 28). This value is typical of $\mathrm{CH}_{3} \mathrm{I}$ dissociatively adsorbed on metal or metal oxide surfaces as previously observed (e.g., $\left.\mathrm{Ni}(100), \mathrm{TiO}_{2}\right)^{59}, 60$. Similarly, a characteristic shift $\left(\sim 1 \mathrm{~cm}^{-1}\right)$ of the signature $\nu(\mathrm{C}-\mathrm{N})$ vibrational mode is observed with FT-IR upon $\mathrm{CH}_{3} \mathrm{I}$ loading of MIL-101-Cr-TED and MIL-101-Cr-HMTA (Fig. 4g, h). These results suggest the formation of strong chemical bonds between tertiary amines and $\mathrm{CH}_{3} \mathrm{I}$, yielding ionic species $\left(\mathrm{R}_{3} \mathrm{~N}-\mathrm{CH}_{3}\right)^{+} \mathrm{I}^{-}$at high temperatures (Supplementary Fig. 29).

To test this hypothesis, we performed an ion-exchange experiment by using an anionic organic dye as a molecular probe. UV-vis measurements were used to monitor the adsorption efficiency of Orange G (OG) dye by the pristine MIL-101-CrTED and MIL-101-Cr-HMTA, as well as $\mathrm{CH}_{3}$ I-loaded MIL-101Cr-TED and MIL-101-Cr-HMTA (Fig. 4i and Supplementary Fig. 30). Fast anion-exchange kinetics were observed when using $\mathrm{CH}_{3}$ I-loaded MIL-101-Cr-TED and MIL-101-Cr-HMTA as adsorbents, which adsorb over $95 \%$ of the anionic organic dye within $1 \mathrm{~min}$ and $30 \mathrm{~s}$, respectively. In contrast, pristine MIL-101Cr-TED and MIL-101-Cr-HMTA samples adsorb only 44 and $54 \%$ of the OG and over a much longer time period of $30 \mathrm{~min}$. The fast kinetics of $\mathrm{CH}_{3}$ I-loaded samples confirms the formation of $\left(\mathrm{R}_{3} \mathrm{~N}_{-} \mathrm{CH}_{3}\right)^{+} \mathrm{I}^{-}$in high concentration when reacting $\mathrm{CH}_{3} \mathrm{I}$ with the free nitrogen atom of the amine molecules grafted on MIL-101-Cr-TED and MIL-101-Cr-HMTA at high temperature. In addition, the formation of $\mathrm{I}^{-}$ions after $\mathrm{CH}_{3} \mathrm{I}$ sorption was verified by $\mathrm{AgNO}_{3}$ titration of dye exchanged filtrates, which yielded AgI precipitate (Supplementary Fig. 31).

To better understand the relationship between the chemisorption and physisorption binding regime at different temperatures, we conducted simulations of the corresponding binding mechanisms (Supplementary Table 7). In particular, we performed an ab initio transition-state search to find the pathway that connects the two regimes and the energy barrier that separates them (see Supplementary Fig. 32). We find that an energy barrier of 459 $\mathrm{meV}$ separates the physisorption and chemisorption case while the energy difference for the products is $200 \mathrm{meV}$ higher than that of the reactants (Supplementary Fig. 32). This energy difference is small enough at room temperature to allow some ionic $\mathrm{I}^{-}$to be present in the system, but large enough to prevent most $\mathrm{CH}_{3}$ from having covalently bonding to the nitrogen in TED. This finding is also consistent with our experimental results (Supplementary Figs. 33 and 34). Once the temperature increases to $150^{\circ} \mathrm{C}$, enough energy enters the system to overcome the energy barrier, resulting in the increased concentration of $\mathrm{CH}_{3}$ covalently bound to TED, which explains the experimentally observed higher amount of $\mathrm{CH}_{3} \mathrm{I}$ chemisorption (Supplementary Table 8).

\section{Discussion}

Incorporating tertiary amine molecules within MIL-101-Cr gives rise to function-adjustable ROI molecular traps with record-high uptake capacities for ROIs capture from nuclear waste. In addition, these molecular traps exhibit excellent recyclability, which is not available for any currently known industrial adsorbents. Coupled with its exceptionally high chemical and thermal stability, high adsorption efficiency at a wide temperature range, and low cost, such molecular traps offer significant promise for ROIs capture from nuclear waste. We anticipate that such crystalline porous materials will become a new platform for effective capture of ROIs and that new molecular traps with optimized frameworks and improved performance will be developed in the near future.

\section{Methods}

Materials and measurements. Commercially available reagents were purchased in high purity and used without further purification. PXRD data were collected on a Rigaku Ultima-IV diffractometer or a Bruker AXS D8 Advance A25 Powder $\mathrm{X}$-ray diffractometer. $\mathrm{N}_{2}$ gas sorption experiments were carried out on a Micromeritics 3 Flex volumetric adsorption analyzer. Elemental analyses were performed on a Perkin-Elmer 2400 element analyzer. TGA was analyzed by a Q5000 thermogravimetric analyzer. The in situ infrared spectroscopic data were obtained using a Nicolet 6700 FTIR spectrometer (purchased from Thermo Scientific Inc, USA) equipped with a liquid $\mathrm{N}_{2}$-cooled mercury cadmium telluride MCT-A detector. A vacuum cell, purchased from Specac Ltd, UK (product number P/N $5850 \mathrm{c}$ ), was placed in the sample compartment of the infrared spectrometer with the sample at the focal point of the beam (Supplementary Fig. 35). The MOFs (powder, $\sim 2 \mathrm{mg}$ ) were gently pressed onto a $\mathrm{KBr}$ pellet $(\sim 1.3 \mathrm{~cm}$ diameter, $1-2 \mathrm{~mm}$ thick) and placed in the cell. The samples were first activated under atmospheric $\mathrm{N}_{2}$ flow at $150^{\circ} \mathrm{C}$ for $3 \mathrm{~h}$ and then evacuated (base pressure $<20$ mtorr) for $\mathrm{CH}_{3} \mathrm{I}$ vapor exposure measurement. The infrared data were recorded during the vapor exposure. XPS measurements were performed on an ESCALAB 250 X-ray photoelectron spectroscopy, using $\mathrm{Mg} \mathrm{K} \alpha \mathrm{X}$-ray as the excitation source. UV-Vis data were collected using a Shimadzu UV-3600 spectrophotometer. HRTEM-EDS analysis was performed in a FEI Tecnai G2 S-Twin with a field emission gun operating at $200 \mathrm{kV}$. Images were acquired digitally on a Gatan multiple CCD camera. The FEI Tecnai G2S-Twin is equipped with an EDS detector, which was used for elemental analysis of the nanocrystal composition. The ${ }^{1} \mathrm{H}$ NMR data were collected on a Bruker AVANCE IIIHD console with $1.9 \mathrm{~mm}$ MAS probe. ICP was performed on a Perkin-Elmer Elan DRC II quadrupole inductively coupled plasma mass spectrometer (ICP-MS) analyzer. $\mathrm{CH}_{3} \mathrm{I}$ adsorption experiments were carried out on a homemade gravimetric adsorption analyzer modified from a thermogravimetric analyzer Q50 (TA Instruments).

Synthesis of MIL-101-Cr. MIL-101-Cr was synthesized according to the reported procedure with minor modifications ${ }^{61}$. Typically, a solution containing chromium(III) nitrate $\mathrm{Cr}\left(\mathrm{NO}_{3}\right)_{3} \cdot 9 \mathrm{H}_{2} \mathrm{O}(800 \mathrm{mg}, 2.0 \mathrm{mmol}), \mathrm{HNO}_{3}(2.0 \mathrm{mmol})$, benzene-1,4-dicarboxylic acid (328 mg, $2.0 \mathrm{mmol}$ ), and $10 \mathrm{~mL} \mathrm{H}_{2} \mathrm{O}$ was transferred to the PTFE/Teflon liner in a hydrothermal autoclave, which is heated at $210^{\circ} \mathrm{C}$ for $8 \mathrm{~h}$ and cooled afterwards slowly to room temperature. The solid product was isolated as a green powder by centrifugation and washed three times with DMF, water, ethanol for $12 \mathrm{~h}$ at $80^{\circ} \mathrm{C}$, respectively. The final product was dried under vacuum at $150^{\circ} \mathrm{C}$ for $24 \mathrm{~h}$.

Synthesis of MIL-101-Cr-TED. A resealable heavy-wall pressure flask was charged with MIL-101-Cr $(1.0 \mathrm{~g})$, TED $(1.5 \mathrm{~g})$, and benzene $(50 \mathrm{~mL})$. The flask was sealed and heated to $110^{\circ} \mathrm{C}$ for 3 days. The green solid of MIL-101-Cr-TED was collected after washing the product with dry benzene, and then drying under vacuum at $200{ }^{\circ} \mathrm{C}$ for $3 \mathrm{~h}$. Caution: the reaction was performed under high pressure with potential hazards. Elemental analysis: calculated: C: $47.63 \%$; $: 3.97 \%$, N: $6.17 \%$; experimental: C: $47.58 \%$; H: $4.14 \%$; N: $6.38 \%$. ICP: calculated: Cr $17.20 \%$; experimental: Cr: $16.89 \%$.

Synthesis of MIL-101-Cr-HMTA. A similar procedure was used to synthesize MIL-101-Cr-HMTA. MIL-101-Cr (1.0 g), HMTA (1.5 g), and chloroform (50 mL) were loaded in a resealable flask. The flask was sealed and heated to $110{ }^{\circ} \mathrm{C}$ for 3 days. The product was collected, washed with dry chloroform, and then dried under vacuum at $200^{\circ} \mathrm{C}$ for $3 \mathrm{~h}$ to yield the green solid, MIL-101-Cr-HMTA Caution: the reaction was performed under high pressure with potential hazards. Elemental analysis: calculated: C: $44.86 \%$; H: $3.74 \%$, N: $11.63 \%$; experimental: C: $44.87 \%$; H: $4.08 \%$; N: $12.15 \%$. ICP: calculated: Cr: $16.20 \%$; experimental: Cr: $15.87 \%$. 
Synthesis of benchmark materials. The detail of synthesizing benchmark materials can be found in Supplementary Methods.

Organic iodide and $\mathbf{I}_{\mathbf{2}}$ adsorption measurements. $\mathrm{CH}_{3} \mathrm{I}$ adsorption experiments were carried out on a homemade gravimetric adsorption analyzer modified from a thermogravimetric analyzer Q-50 (TA Instruments). In a typical adsorption experiment, $\sim 20 \mathrm{mg}$ adsorbent sample was loaded on the thermobalance and activated at $200^{\circ} \mathrm{C}$ for $2 \mathrm{~h}$ under $\mathrm{N}_{2}$ flow to ensure complete removal of residue solvents in the sample. The temperature was then reduced to either 30 or $150^{\circ} \mathrm{C}$ and the gas flow was switched from pure $\mathrm{N}_{2}$ to a combination of a pure $\mathrm{N}_{2}$ gas stream and another $\mathrm{N}_{2}$ gas stream passing through a $\mathrm{CH}_{3} \mathrm{I}$ bubbler. The flow rates of the two gas streams were controlled via two gas flow controllers to achieve certain partial pressures. The adsorption amount was monitored by recording the sample weight. The gas flow was switched back to pure $\mathrm{N}_{2}$ after a plateau was reached. The sorption data of $\mathrm{CH}_{3} \mathrm{CH}_{2} \mathrm{I}$ and $\mathrm{CH}_{3} \mathrm{CH}_{2} \mathrm{CH}_{2} \mathrm{I}$ were collected under the same experimental procedure at $150{ }^{\circ} \mathrm{C}$ with a partial pressure of 0.1 and 0.05 atm, respectively. $\mathrm{I}_{2}$ adsorption isotherms were also obtained following a similar procedure at $150^{\circ} \mathrm{C}$ with the $\mathrm{I}_{2}$ concentration at $150 \mathrm{ppm}$.

Breakthrough experiment with or without humidity. The breakthrough experiment was conducted using a lab-scale fixed-bed reactor at $150^{\circ} \mathrm{C}$ (Supplementary Fig. 36). In a typical experiment, the powder was activated at $150^{\circ} \mathrm{C}$ for 3 h. Then $1.0 \mathrm{~g}$ of material was packed into a quartz column $(5.8 \mathrm{~mm} \mathrm{I.D.} \times 150 \mathrm{~mm})$ with silane-treated glass wool filling the void space. A helium flow $\left(5 \mathrm{~cm}^{3} \mathrm{~min}^{-1}\right)$ was used to purge the adsorbent. The flow of He was then turned off while dry $\mathrm{N}_{2}$ at a rate of $5 \mathrm{~mL} \mathrm{~min}^{-1}$ bubbled through $\mathrm{CH}_{3} \mathrm{I}$ and was allowed to flow into the column. The flow rate of $\mathrm{CH}_{3} \mathrm{I}$ was $8.872 \mathrm{mg} \mathrm{min}^{-1}\left(1.4 \mathrm{~cm}^{3} \mathrm{~min}^{-1}\right)$, determined through trial and error. The effluent from the column was monitored using an online mass spectrometer (MS). Experiments in the presence of humidity were performed by injecting water into the gas mixture at a rate of $0.12 \mu \mathrm{L} \mathrm{min}^{-1}$ using a Fusion 100 syringe pump.

The absolute adsorbed amount of gas $i\left(q_{i}\right)$ is calculated from the breakthrough curve by the equation:

$$
q_{\mathrm{i}}=\frac{F_{\mathrm{i}} \times t_{0}-V_{\text {dead }}-\int_{0}^{t_{0}} F_{\mathrm{e}} \Delta t}{m}
$$

where $F_{\mathrm{i}}$ is the influent flow rate of the specific gas $\left(\mathrm{cm}^{3} \mathrm{~min}^{-1}\right) ; t_{0}$ is the adsorption time (min); $V_{\text {dead }}$ is the dead volume of the system $\left(\mathrm{cm}^{3}\right) ; F_{\mathrm{e}}$ is the effluent flow rate of the specific gas $\left(\mathrm{cm}^{3} \mathrm{~min}^{-1}\right)$; and $m$ is the mass of the sorbent $(\mathrm{g})$.

It should be mentioned that the loading amounts obtained from the breakthrough experiments are slightly different from those from adsorption isotherm measurements. This discrepancy is mainly due to small errors associated with factors such as sample particle size, packing length, and packing density.

Decontamination factor measurements. Decontamination factors (DFs) were measured using a similar system as breakthrough experiment. The concentration of $\mathrm{CH}_{3} \mathrm{I}$ was $50 \mathrm{ppm}$ with or without $\mathrm{I}_{2}(150 \mathrm{ppm}) .5 \mathrm{M}$ nitric acid solution was introduced into a bubbler to allow the $\mathrm{N}_{2}\left(12 \mathrm{~mL} \mathrm{~min}^{-1}\right)$ to carry the nitric acid and moisture vapors into the system, and the $\mathrm{RH}$ was $95 \%\left(23^{\circ} \mathrm{C}\right)$. Heated lines temperature was kept at $150{ }^{\circ} \mathrm{C}$ to get in situ formation of $\mathrm{NO}_{\mathrm{x}}$ during heating. The residual $\mathrm{CH}_{3} \mathrm{I}$ and $\mathrm{I}_{2}$ were collected at interval time by $\mathrm{NaOH}$ bubbler and tested by ICP-MS. The DFs were calculated based on the ICP-MS data.

Ab initio calculations. Our ab initio calculations were performed at the density functional theory (DFT) level as implemented in the VASP ${ }^{62}$, 63 software, using the vdW-DF exchange-correlation function ${ }^{64,65}$. We used PAW potentials with energy cutoff values of $600 \mathrm{eV}$ and energies were converged to within $1 \times 10^{-4} \mathrm{eV}$. Transition states were found with a common transition-state search algorithm.

lon-exchange experiments. A $10 \mathrm{~mL}$ aqueous solution of Orange $\mathrm{G}(0.073 \mathrm{mM})$ was added to a $20 \mathrm{~mL}$ vial, which was followed by addition of $30.0 \mathrm{mg}$ of the respective MOF sample to form slurry at room temperature. During the stirring period, a small amount of mixture was drawn $(\sim 0.5 \mathrm{~mL})$ and filtered immediately at selected time intervals through a 0.45 micron membrane filter, and the filtrates were analyzed using UV-vis spectroscopy to determine the concentration of the Orange $\mathrm{G}$ ions.

Data availability. The data that support the findings of this study are available from the corresponding author on reasonable request.
Received: 15 November 2016 Accepted: 5 July 2017

Published online: 07 September 2017

\section{References}

1. World energy needs and nuclear power. World Nuclear Association http://www. world-nuclear.org/information-library/current-and-future-generation/worldenergy-needs-and-nuclear-power.aspx.

2. Haefner, D. R. \& Tranter, T. J. Methods of Gas Phase Capture of Iodine from Fuel Reprocessing Off-Gas: a Literature Survey. Report No. INL/EXT-07-12299 (Idaho National Laboratory, 2007).

3. Clément, B. et al. State of the Art Report on Iodine Chemistry. Report No. NEA/ CSNI/R(2007)1 (International Atomic Energy Agency/International Nuclear Information System, 2007).

4. Bruffey, S. H. et al. A Literature Survey to Identify Potentially Problematic Volatile Iodine-Bearing Species Present in Off-Gas Streams. Report No. FCRDMRWFD-2015-000421, ORNL-SPR-2015/290, INL/EXT-15-35609 (2015).

5. Bruffey, S. H., Jubin, R. T. \& Jordan, J. A. Organic Iodine Adsorption by AgZ under Prototypical Vessel Off-Gas Conditions. Report No. FCRD-MRWFD2016-000357; ORNL/TM-2016/568 (2016).

6. Adams, R. E. et al. The Release and Adsorption of Methyl Iodide in the HFIR Maximum Credible Accident. Report No. ORNL-TM-1291 (1965).

7. Jubin, R. T. A Literature Survey of Methods to Remove Iodine from Off-Gas Streams Using Solid Sorbents. Report No. ORNL/TM-6607 (Oak Ridge National Laboratory, 1979).

8. Park, S. W., Park, H. S., Lee, W. K. \& Moon, H. Effect of water vapor on adsorption of methyl iodide to triethylenediamine-impregnated activated carbons. Separ. Technol 5, 35-44 (1995).

9. González-García, C. M., González, J. F. \& Román, S. Removal efficiency of radioactive methyl iodide on TEDA-impregnated activated carbons. Fuel Process. Technol. 92, 247-252 (2011).

10. Jubin, R. Organic Iodine Removal from Simulated Dissolver Off-Gas Systems Utilizing Silver Exchanged Mordenite. Report No. CONF-811108-14 (Oak Ridge National Laboratory, 1981).

11. Chapman, K. W., Chupas, P. J. \& Nenoff, T. M. Radioactive iodine capture in silver-containing mordenites through nanoscale silver iodide formation. J. Am. Chem. Soc. 132, 8897-8899 (2010).

12. Nenoff, T. M., Rodriguez, M. A., Soelberg, N. R. \& Chapman, K. W. Silvermordenite for radiologic gas capture from complex streams: dual catalytic $\mathrm{CH}_{3} \mathrm{I}$ decomposition and I confinement. Micropor. Mesopor. Mat 200, 297-303 (2014).

13. Funabashi, K., Fukasawa, T. \& Kikuchi, M. Investigation of silver-impregnated alumina for removal of radioactive methyl iodide. Nucl. Technol. 109, 366-372 (1995).

14. Scheele, R. D., Burger, L. L. \& Matsuzaki, C. L. Methyl Iodide Sorption By Reduced Silver Modernite. Reort No. PNL-4489 (Pacific National Lab, 1983).

15. Pham, T. C. T. et al. Capture of iodine and organic iodides using silica zeolites and the semiconductor behaviour of iodine in a silica zeolite. Energy Environ. Sci. 9, 1050-1062 (2016).

16. Hebel, W. \& Cottone, G. Management Modes for Iodine-129, Radioactive Waste Management Series, Vol. 7 (Harwood Academic Publishers, 1982).

17. Zhou, H.-C., Long, J. R. \& Yaghi, O. M. Introduction to metal-organic frameworks. Chem. Rev. 112, 673-674 (2012).

18. Furukawa, H., Cordova, K. E., O’Keeffe, M. \& Yaghi, O. M. The chemistry and applications of metal-organic frameworks. Science 341, 1230444 (2013).

19. Sun, Q. et al. Imparting amphiphobicity on single-crystalline porous materials. Nat. Commun. 7, 13300 (2016).

20. Nugent, P. et al. Porous materials with optimal adsorption thermodynamics and kinetics for $\mathrm{CO}_{2}$ separation. Nature 495, 80-84 (2013).

21. Hu, Z., Deibert, B. J. \& Li, J. Luminescent metal-organic frameworks for chemical sensing and explosive detection. Chem. Soc. Rev. 43, 5815-5840 (2014).

22. Ameloot, R. et al. Interfacial synthesis of hollow metal-organic framework capsules demonstrating selective permeability. Nat. Chem 3, 382-387 (2011).

23. Zhao, X. et al. Selective anion exchange with nanogated isoreticular positive metal-organic frameworks. Nat. Commun. 4, 2344 (2013).

24. Xiang, S. et al. Microporous metal-organic framework with potential for carbon dioxide capture at ambient conditions. Nat. Commun. 3, 954 (2012).

25 . An, J. et al. Metal-adeninate vertices for the construction of an exceptionally porous metal-organic framework. Nat. Commun. 3, 604 (2012).

26. He, H. et al. Polarized three-photon-pumped laser in a single MOF microcrystal. Nat. Commun. 7, 11087 (2016).

27. Ma, L. et al. A series of isoreticular chiral metal-organic frameworks as a tunable platform for asymmetric catalysis. Nat. Chem 2, 838-846 (2010). 
28. Cui, X. et al. Pore chemistry and size control in hybrid porous materials for acetylene capture from ethylene. Science 353, 141-144 (2016).

29. Farha, O. K. et al. De novo synthesis of a metal-organic framework material featuring ultrahigh surface area and gas storage capacities. Nat. Chem 2, 944-948 (2010).

30. Yuan, D., Zhao, D., Sun, D. \& Zhou, H.-C. An isoreticular series of metal-organic frameworks with dendritic hexacarboxylate ligands and exceptionally high gas-uptake capacity. Angew. Chem. Int. Ed. 49, 5357-5361 (2010).

31. Li, B. et al. Enhanced binding affinity, remarkable selectivity, and high capacity of $\mathrm{CO}_{2}$ by dual functionalization of a rht-type metal-organic framework. Angew. Chem. Int. Ed. 51, 1412-1415 (2012).

32. Hughes, J. T., Sava, D. F., Nenoff, T. M. \& Navrotsky, A. Thermochemical evidence for strong iodine chemisorption by ZIF-8. J. Am. Chem. Soc. 135, 16256-16259 (2013).

33. Chapman, K. W. et al. Trapping guests within a nanoporous metal-organic framework through pressure-induced amorphization. J. Am. Chem. Soc. 133, 18583-18585 (2011)

34. Sava, D. F. et al. Capture of volatile iodine, a gaseous fission product, by zeolitic imidazolate framework-8. J. Am. Chem. Soc. 133, 12398-12401 (2011).

35. Zeng, M.-H. et al. Rigid pillars and double walls in a porous metal-organic framework: single-crystal to single-crystal, controlled uptake and release of iodine and electrical conductivity. J. Am. Chem. Soc. 132, 2561-2563 (2010).

36. Motkuri, R. K. et al. Fluorocarbon adsorption in hierarchical porous frameworks. Nat. Commun. 5, 4368 (2014).

37. Banerjee, D. et al. Metal-organic framework with optimally selective xenon adsorption and separation. Nat. Commun. 7, 11831 (2016).

38. Sato, H. et al. Self-accelerating CO sorption in a soft nanoporous crystal. Science 343, 167-170 (2014)

39. Sakata, Y. et al. Shape-memory nanopores induced in coordination frameworks by crystal downsizing. Science 339, 193-196 (2013).

40. Vaidhyanathan, R. et al. Direct observation and quantification of $\mathrm{CO}_{2}$ binding within an amine-functionalized nanoporous solid. Science 330, 650-653 (2010).

41. Herm, Z. R. et al. Separation of hexane isomers in a metal-organic framework with triangular channels. Science 340, 960-964 (2013).

42. Li, B. et al. Metal-organic framework based upon the synergy of a Brønsted acid framework and Lewis acid centers as a highly efficient heterogeneous catalyst for fixed-bed reactions. J. Am. Chem. Soc. 137, 4243-4248 (2015).

43. Wang, Z. \& Cohen, S. M. Postsynthetic modification of metal-organic frameworks. Chem. Soc. Rev. 38, 1315-1329 (2009).

44. Férey, G. et al. A chromium terephthalate-based solid with unusually large pore volumes and surface area. Science 309, 2040-2042 (2005).

45. Hwang, Y. K. et al. Amine grafting on coordinatively unsaturated metal centers of MOFs: consequences for catalysis and metal encapsulation. Angew. Chem. Int. Ed. 47, 4144-4148 (2008).

46. Li, B. et al. A strategy toward constructing a bifunctionalized MOF catalyst: post-synthetic modification of MOFs on organic ligands and coordinatively unsaturated metal sites. Chem. Commun. 48, 6151-6153 (2012).

47. Banerjee, M. et al. Postsynthetic modification switches an achiral framework to catalytically active homochiral metal-organic porous materials. J. Am. Chem. Soc. 131, 7524-7525 (2009).

48. Sava, D. F. et al. Competitive $\mathrm{I}_{2}$ sorption by Cu-BTC from humid gas streams. Chem. Mater. 25, 2591-2596 (2013).

49. Riley, B. J. et al. Materials and processes for the effective capture and immobilization of radioiodine: a review. J. Nucl. Mater. 470, 307-326 (2016).

50. Cohen, S. M. Postsynthetic methods for the functionalization of metal-organic frameworks. Chem. Rev. 112, 970-1000 (2012).

51. Canivet, J., Aguado, S., Schuurman, Y. \& Farrusseng, D. MOF-supported selective ethylene dimerization single-site catalysts through one-pot postsynthetic modification. J. Am. Chem. Soc. 135, 4195-4198 (2013).

52. Weiss, G. S., Parkes, A. S., Nixon, E. R. \& Hughes, R. E. Vibrational spectra and the structure of crystalline triethylenediamine. J. Chem. Phys. 41, 3759-3767 (1964).

53. Bernstein, M. P., Sandford, S. A., Allamandola, L. J. \& Chang, S. Infrared spectrum of matrix-isolated hexamethylenetetramine in $\mathrm{Ar}$ and $\mathrm{H}_{2} \mathrm{O}$ at cryogenic temperatures. J. Chem. Phys. 98, 12206-12210 (1994).

54. Zorn, G. et al. X-ray photoelectron spectroscopy investigation of the nitrogen species in photoactive perfluorophenylazide-modified surfaces. J. Phys. Chem. C 118, 376-383 (2014).
55. Mao, C. et al. Anion stripping as a general method to create cationic porous framework with mobile anions. J. Am. Chem. Soc. 136, 7579-7582 (2014).

56. Soelberg, N. \& Watson, T. FY-2015 Methyl Iodide Deep-Bed Adsorption Test Report. Report No. FCRD-MRWFD-2015-000267, INL/EXT-15-36817 (2015).

57. Jubin, R. T., Soelberg, N. R., Strachan, D. M. \& Ilas, G. Fuel Age Impacts on Gaseous Fission Product Capture During Separations. Report No. FCRD-SWF2012-000089, PNNL-22550 (2012).

58. Hoffmann, H. C. et al. Solid-state NMR spectroscopy of metal-organic framework compounds (MOFs). Materials 5, 2537-2572 (2012).

59. Tjandra, S. \& Zaera, F. Methyl iodide thermal reactions when chemisorbed on nickel(100) surfaces. Langmuir 8, 2090-2097 (1992).

60. Garrett, S. J. et al. The adsorption and photochemistry of $\mathrm{CD}_{3} \mathrm{I}$ on $\mathrm{TiO}_{2}(110)$ J. Chem. Phys. 100, 4615 (1994).

61. Zhao, T. et al. High-yield, fluoride-free and large-scale synthesis of MIL-101 (Cr). Dalton Trans. 44, 16791-16801 (2015).

62. Kresse, G. \& Furthmüller, J. Efficient iterative schemes for ab initio total-energy calculations using a plane-wave basis set. Phys. Rev. B 54, 11169-11186 (1996).

63. Kresse, G. \& Joubert, D. From ultrasoft pseudopotentials to the projector augmented-wave method. Phys. Rev. B 59, 1758-1775 (1999).

64. Thonhauser, T. et al. Spin signature of nonlocal correlation binding in metalorganic frameworks. Phys. Rev. Lett. 115, 136402 (2015).

65. Berland, K. et al. van der Waals forces in density functional theory: a review of the vdW-DF method. Rep. Prog. Phys. 78, 066501 (2015)

\section{Acknowledgements}

Financial support from the Materials Sciences and Engineering Division, Office of Basic Research Energy Sciences of the U.S. Department of Energy through Grant No. DE-FG02-08ER-46491 is gratefully acknowledged.

\section{Author contributions}

J.L. and B.L. conceived and designed the research. J.L. and B.L. co-wrote the manuscript. B.L. carried out the materials design, synthesis, and part of characterizations as well as ion exchange experiment. X.D. and Y.H. conducted column breakthrough experiments under dry and humid conditions, as well as decontamination factors analysis. H.W. collected and analyzed $\mathrm{CH}_{3} \mathrm{I}$ adsorption isotherm data at different temperatures. B.J.D. D.M., Z.S., K.T., J.B., J.C., and Y.J.C. contributed to material characterization by various spectroscopic methods. S.J. and T.T. performed theoretical calculations. All authors contributed to the discussion of results and commented on the manuscript.

\section{Additional information}

Supplementary Information accompanies this paper at doi:10.1038/s41467-017-00526-3.

Competing interests: The authors declare no competing financial interests.

Reprints and permission information is available online at http://npg.nature.com/ reprintsandpermissions/

Publisher's note: Springer Nature remains neutral with regard to jurisdictional claims in published maps and institutional affiliations.

Open Access This article is licensed under a Creative Commons Attribution 4.0 International License, which permits use, sharing, adaptation, distribution and reproduction in any medium or format, as long as you give appropriate credit to the original author(s) and the source, provide a link to the Creative Commons license, and indicate if changes were made. The images or other third party material in this article are included in the article's Creative Commons license, unless indicated otherwise in a credit line to the material. If material is not included in the article's Creative Commons license and your intended use is not permitted by statutory regulation or exceeds the permitted use, you will need to obtain permission directly from the copyright holder. To view a copy of this license, visit http://creativecommons.org/ licenses/by/4.0/

(C) The Author(s) 2017 